\title{
The complex interaction between atrial fibrillation and heart failure in elderly patients
}

\author{
Stefano Fumagalli, Giulia Pelagalli, Marta Migliorini, Serena Boni, Francesca Nigro, Irene Marozzi, \\ Simone Pupo, Niccolò Marchionni \\ Geriatric Intensive Care Unit and Geriatric Arrhythmia Unit, Department of Experimental and Clinical Medicine, \\ University of Florence and AOU Careggi, Florence, Italy
}

\begin{abstract}
Heart failure (HF) and atrial fibrillation (AF) often coexist. Subjects with permanent AF show the highest prevalence of HF. Patients with incident AF have HF in a great number of cases and, reciprocally, in patients with incident $\mathrm{HF}$, an $\mathrm{AF}$ can be frequently found. The simultaneous presence of the two conditions is associated with mortality rates higher than those observed in individuals with only one or none of them. Interestingly, HF and AF could synergistically promote in elderly patients the development of disability and dementia. Inflammatory mechanisms coupled with changes of renin-angiotensin system, hormonal pathways and neuro-mediators could simultaneously promote left atrium remodeling and sustain both HF and AF. Beta-blockers and digoxin seem to have small therapeutic effect and limited influence on prognosis in these very complex patients. Sinus rhythm restoration could slow down the progression of disability in symptomatic subjects. Recent evidence seem to suggest that upstream therapy coupled with rehabilitation, and that AV node ablation associated with cardiac resynchronization therapy could benefit subjects with HF and AF. In conclusion, elderly patients simultaneously presenting problems of cardiac function and arrhythmia are an important challenge for geriatric medicine, and request important efforts to improve their functional profile and prognosis.
\end{abstract}

\footnotetext{
Correspondence: Stefano Fumagalli, Geriatric Intensive Care Unit and Geriatric Arrhythmia Unit, Department of Experimental and Clinical Medicine, University of Florence and AOU Careggi, Viale G. Pieraccini 6. 50139 Florence, Italy.

Tel. +39.055.2758135.

E-mail: stefano.fumagalli@unifi.it
}

Key words: Atrial fibrillation; dementia; disability; elderly; heart failure.

Received for publication: 15 February 2019.

Accepted for publication: 15 May 2019.

CCopyright S. Fumagalli et al., 2019

Licensee PAGEPress, Italy

Monaldi Archives for Chest Disease 2019; 89:1050

doi: 10.4081/monaldi.2019.1050

This article is distributed under the terms of the Creative Commons Attribution Noncommercial License (by-nc 4.0) which permits any noncommercial use, distribution, and reproduction in any medium, provided the original author(s) and source are credited.

\section{The epidemiologic insight of the problem}

Heart failure (HF) has a high prevalence in patients with atrial fibrillation (AF), and, reciprocally, $\mathrm{AF}$ has a high prevalence in patients with $\mathrm{HF}$, as demonstrated by the specific age-related results of some registries and population-based studies (Table 1). The results of the EURObservational Research Programme on Atrial Fibrillation (EORP-AF) Long-Term General Registry, which enrolled subjects showing at least one arrhythmia episode in the last 12 months, demonstrated that $\mathrm{HF}$ was the main reason for admission in hospital or consultation in $10.4 \%$ of the whole population. The proportion of patients with HF significantly differed according to the type of AF, ranging from a minimum of $4.6 \%$, for paroxysmal AF, to $19.7 \%$, for permanent AF (Figure 1) [1].

Most of the new cases of the arrhythmia develop in the 5 years preceding and following the diagnosis of HF [2]. Indeed, the concepts that AF begets $\mathrm{HF}$ and that HF begets $\mathrm{AF}$ are now widely accepted. More in detail, in the Framingham Heart Study, among the 1737 subjects with new onset AF (mean age: $75 \pm 12$ years), a diagnosis of HF was found in 37\% of cases, while among the 1166 participants with incident HF (mean age: $79 \pm 11$ years), the prevalence of AF was $62 \%$. Accordingly, the risk to develop the arrhythmia was more than two times higher in $\mathrm{HF}$ patients $(\mathrm{HR}=2.18$; 95\% $\mathrm{CI}=1.26-3.76$ ), similar to the risk of incident $\mathrm{HFpEF}-\mathrm{HF}$ with preserved ejection fraction $(\mathrm{EF})-(\mathrm{HR}=2.34$; $95 \% \mathrm{CI}=1.48$ 3.70), and higher than the risk of a new HFrEF - HF with reduced $\mathrm{EF}-(\mathrm{HR}=1.32 ; 95 \% \mathrm{CI}=0.83-2.10)$ in $\mathrm{AF}$ subjects [3].

\section{From epidemiology to pathophysiology and vice versa}

HF and AF have an interrelated pathophysiology. In fact, some characteristics of $\mathrm{HF}$, such as the increased filling pressures of left ventricle, the higher amount of atrial fibrosis and remodeling, the activation of neuro-hormonal pathways, and the triggering of pulmonary veins automaticity can promote arrhythmia development. Furthermore, in AF patients, left ventricular hypertrophy could be also a marker of an abnormal ankle-brachial index, thus unrevealing the presence of a significant arterial disease [4]. At the same time, AF with rapid and irregular ventricular rates and the reduced cardiac output can originate or worsen HF [5]. Epidemiological data showed that, in elderly individuals, the persistent forms of the arrhythmia can be associated with clinical and laboratory variables typical of a frail condition [6]. More recently, the pre-ablation study of patients with paroxysmal AF evidenced values of 


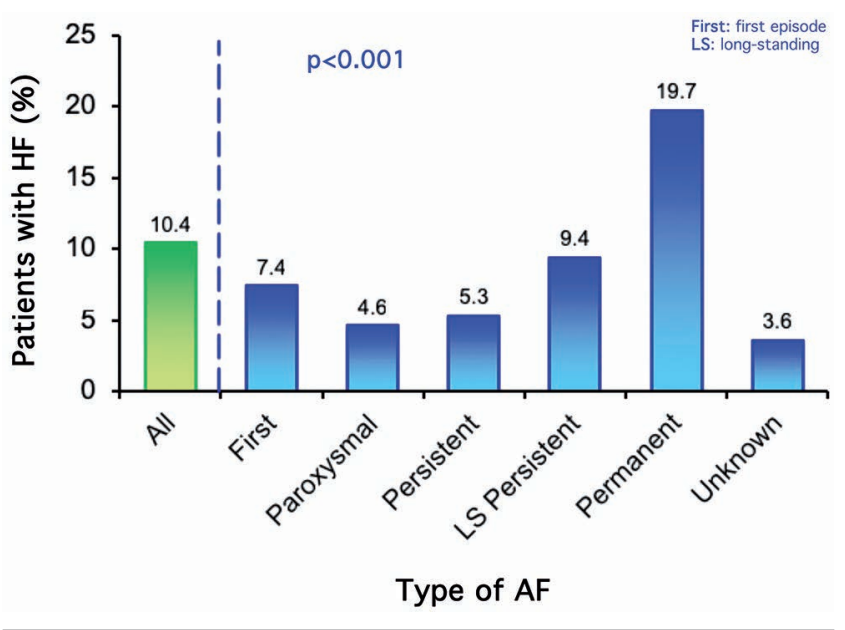

Figure 1. Heart failure (HF) as the main reason for admission in hospital / consultation by type of atrial fibrillation (AF) in the 11096 patients enrolled in the EURObservational Research Programme on Atrial Fibrillation (EORP-AF) Long-Term General Registry. Adapted from: Table 2, Boriani et al. Europace 2018;20:747-57, doi:10.1093/europace/eux301, with permission of the Oxford University Press on behalf of the European Society of Cardiology. This material is not included under the open access license of this publication. myocardial energetics and left ventricular EF lower than those observed in controls with stable sinus rhythm. These findings let us hypothesize that even lone AF could be a marker of an occult cardiomyopathy characterized by a subtle LV dysfunction [7]. Indeed, the impact of AF on mortality is significant and additive to that of HF, particularly at an advanced age. The Cardiovascular Health Study Investigators demonstrated in 5673 subjects (mean age: 73 years) followed up for 13 years that mortality grew form $43 \%$, in those without AF and HF, to $66 \%$ (AF present) and 74\% (HF present), to reach $85 \%$ in individuals with both conditions. Basing on these findings, the simultaneous presence of AF and HF was associated with a three times higher mortality risk [8]. The Framingham Heart Study results confirm these findings. During the follow-up, which was stopped after a length of 8 years, both HFrEF $(\mathrm{HR}=2.73 ; 95 \% \mathrm{CI}=2.12-3.48)$ and $\mathrm{HFpEF} \quad(\mathrm{HR}=1.83$; $95 \% \mathrm{CI}=1.41-2.37)$ were associated with a significantly increased mortality risk after a new episode of AF [3].

$\mathrm{HF}$ and AF are important in the elderly not only for their adverse effects on survival. Incident dementia and disability are associated with the arrhythmia [9]. In fact, the loss of atrial contraction and of atrio-ventricular synchrony, which characterize AF, lead to the reduction of LV systolic function and cardiac output. These modifications, through heart failure and stroke development, can further originate alterations of physical performance, functional status and neuro-cognitive profile [9]. Some evidence supports these associations. First, in the Framingham Heart Study, MRI scans showed that cardiac index reduction was related to a parallel decrease of total brain volume [10]. Interestingly, later, the AGES-Reykjavik Study found an intriguing inverse association between the arrhythmia burden (i.e., sinus rhythm vs. paroxysmal

Table 1. Specific age-oriented epidemiological associations between heart failure and atrial fibrillation in some registries and population-based studies.

\begin{tabular}{|c|c|c|c|}
\hline Study & Type of study & Age-related result & Reference \\
\hline $\begin{array}{l}\text { Acute Decompensated } \\
\text { Heart Failure National } \\
\text { Registry (ADHERE) }\end{array}$ & In-hospital patients & $\begin{array}{l}\text { Prevalence of } \mathrm{AF} \text { in }>70 \text { years } \\
\text { - LVEF }>40 \%: 36 \% \\
\text { - LVEF < < } 30 \%: 41 \%\end{array}$ & $\begin{array}{l}\text { Maisel WH et al. Am J Cardiol 2003; } 91 \\
\text { (6 Suppl 1):2-8 }\end{array}$ \\
\hline Olmsted County Study & Population Study (1990-98) & $\begin{array}{l}\text { 4-year incidence of AF in } \\
>65 \text { years old subjects with } \\
\text { abnormal LV relaxation: } 18 \%\end{array}$ & Tsang TS et al. Am J Cardiol 2004; 93:54-58 \\
\hline $\begin{array}{l}\text { National, Heart, Lung, and Blood } \\
\text { Institute - Sponsored Cardiovascular } \\
\text { Research Network (CVRN) }\end{array}$ & $\begin{array}{l}\text { Discharged from hospital patients } \\
\text { and outpatients(2005-8) }\end{array}$ & $\begin{array}{l}\geq 75 \text { years subjects } \\
\text { - Pre-existing AF: } 65.7 \% \\
\text { - Incident AF: } 56.8 \%\end{array}$ & McManus DD et al. JAMA 2013; 2: e005694 \\
\hline \multirow[t]{2}{*}{$\begin{array}{l}\text { EURObservational Research } \\
\text { Programme (EORP) -AF General } \\
\text { Pilot Registry }\end{array}$} & $\begin{array}{l}\text { Registry of in-hospital and } \\
\text { ambulatory patients with AF } \\
\text { (2012-13) }\end{array}$ & $\begin{array}{l}\text { Prevalence of } \mathrm{HF} \text { in AF patients } \\
\geq 75 \text { years: } 55 \%\end{array}$ & $\begin{array}{l}\text { Fumagalli S et al. JACC: Clinical } \\
\text { Electrophysiology 2015; 1:326-334 }\end{array}$ \\
\hline & $\begin{array}{l}\text { Patients admitted for HF in UK } \\
(2000-13)\end{array}$ & $\begin{array}{l}\text { Prevalence of } \mathrm{AF} \text { in } \\
\text { - } 70-79 \text { years: } 36.8 \% \\
\text { - } 80-89 \text { years: } 42.4 \% \\
\text { - } 90-99 \text { years: } 40.5 \%\end{array}$ & Ziaei F et al. Int J Cardiol 2016: 214:410-1 \\
\hline PREFER in AF & Registry of AF patients (2012-13) & $\begin{array}{l}\text { Prevalence of } \mathrm{HF} \text { in }>80 \text { years } \\
\text { AF subjects: } 30.3 \%\end{array}$ & Hanon 0 et al. Int J Cardiol 2017; 232:98-104 \\
\hline Swedish Heart Failure Registry & Registry of HF patients (2000-12) & $\begin{array}{l}\text { Highest observed AF prevalence } \\
\text { in men > } 90 \text { years with HFpEF: } 77 \%\end{array}$ & $\begin{array}{l}\text { Sartipy U et al. JACC: Heart Failure 2017; } \\
5: 565-574\end{array}$ \\
\hline Framingham Heart Study & Population Study (1968-2014) & $\begin{array}{l}\text { Lifetime risk of AF in } 75 \text { years old } \\
\text { subjects with elevated risk due to } \\
\text { history of HF or MI } \\
\text { (median follow-up: } 8 \text { years): } 35.1 \%\end{array}$ & Staerk L et al. BMJ 2018; 361:k1453 \\
\hline
\end{tabular}

$\mathrm{AF}$, atrial fibrillation; $\mathrm{HF}$, heart failure; $\mathrm{HFpEF}$, heart failure with preserved ejection fraction; LV, left ventricular; LVEF, LV ejection fraction; $\mathrm{MI}$, myocardial infarction. 
AF vs. persistent or permanent AF) and total brain volume, always estimated with MRI [11]. Lastly, in the AF Competence NETwork, it was shown that also learning and memory skills progressively reduced following the arrhythmic burden [12]

\section{The problematic therapy of $\mathrm{AF}$ in $\mathrm{HF}$ patients}

Therapy of HF and AF in elderly individuals presents some relevant controversial issues. HF, especially if associated with AF, acts as a prothrombotic cause. In particular, endothelial dysfunction, blood flow stasis, platelet activation, and the influence on the coagulation cascade contribute to a higher than normal thrombogenic status [13]. Historical data showed that mean daily dose of warfarin in AF patients should be reduced when $\mathrm{HF}$ is present. Indeed, the results of the registrative studies of all the direct anticoagulants seem to be consistent with unaltered drug efficacy and safety in subjects with and without HF [13].

Present Guidelines for the management of AF recommend the use of beta-blockers and digoxin (Class I, Level of Evidence B) for rate control in patients with $\mathrm{HF}$, especially if with reduced EF [14]. However, the results of a meta-analysis found that beta-blocker therapy was effective to reduce mortality and hospital admissions in HF subjects with severe systolic dysfunction only if sinus rhythm was present. The benefit of treatment was lost in patients with AF [15]. Furthermore, even digoxin seems to show no benefits on survival in AF elderly patients independently of the presence of HF [16]. At this regard, a recent sub-analysis of the ARISTOTLE found that the effect of digoxin on mortality, independently of the presence of HF, was apparently neutral in AF patients if treatment was started before the beginning of the study. However, mortality was significantly higher in those individuals who need to begin digoxin therapy during the conduction of the study $(\mathrm{HR}=1.78 ; 95 \% \mathrm{CI}=1.37-2.31)$ [17]. Furthermore, all-cause death was directly related to digoxin concentration, with a greater level of drug in those who died ( 0.62 vs $0.55 \mathrm{ng} / \mathrm{mL}, \mathrm{p}<0.0001)$, and a mortality risk $19 \%$ higher for each $0.5 \mathrm{ng} / \mathrm{mL}$ increase of drug concentration $(\mathrm{HR}=1.19 ; 95 \% \mathrm{CI}=1.07-1.32)$ [17].

Sinus rhythm restoration could represent a useful tool to improve cardiac function in elderly patients with persistent AF. Indeed, in a recent experience, an effective electrical cardioversion produced an improvement of longitudinal strain - a marker of left ventricular performance assessed with speckle tracking analysis of the echocardiogram - in 43 of the 48 (90\%) subjects (age: 73 years) evaluated few hours after the procedure. All segments of the cardiac silhouette showed a better performance [18]. These positive changes could explain the significant increase of physical performance, as evaluated with the Short Physical Performance Battery (SPPB), in those who maintained the sinus rhythm at the follow-up evaluation (mean length: 141 days). Interestingly, no difference was present in those patients in whom $\mathrm{AF}$ relapsed $(\Delta \mathrm{SR} v \mathrm{AF}=$ $+1.1 \pm 0.4, \mathrm{p}=0.018$ ) [19].

Psychological profile seems to exert a relevant role on prognosis of patients with HF and AF. In the AF-CHF trial (mean age: 66 years; left ventricular EF $\leq 35 \%$ ), cardiovascular death was significantly higher in patients with elevated depressive symptoms as assessed with the Beck Depression Inventory (score $\geq 14 / 63$ ). In detail, mild to moderate depression influenced prognosis $(\mathrm{OR}=1.57 ; 95 \% \mathrm{CI}=1.20-2.07)$ more than the choice of the raterhythm-control strategy of the arrhythmia did [20]. Later, always in the same trial, it was shown that the rhythm control strategy of $\mathrm{AF}$ was associated to reduced cardiovascular mortality, when com- pared to the rate-control one $(\mathrm{OR}=0.55 ; 95 \% \mathrm{CI}=0.32-0.95)$, only in those patients with high symptoms of anxiety, as evaluated with the Anxiety Sensitivity Inventory [21].

In the AF population, atrial structure undergoes a continuous remodeling process. Inflammation markers, angiotensin-II, aldosterone, endothelin-1 and the reactive oxygen species interact with the traditional arrhythmia clinical risk-factors and with obesity to change atrial myocardium and to promote AF relapse [22]. Basing on these assumptions, the "routine $v s$. aggressive risk factor driven upstream rhythm control for prevention of early AF in heart failure" (RACE 3) trial compared a conventional approach to a new, "targeted therapy", one to maintain sinus rhythm at the follow-up in patients with $\mathrm{HF}$ and persistent AF. In the active arm, four therapies were introduced: mineralocorticoid receptor antagonists, statins, angiotensin converting enzyme inhibitors and/or receptor blockers, and cardiac rehabilitation, including physical activity, dietary restrictions, and counselling. At the one-year follow-up, the 7-day Holter monitoring demonstrated a higher proportion of patients with sinus rhythm in the "targeted therapy" group ( $75 v s .63 \%, p=0.042)$ [23].

The use of devices for cardiac resynchronization therapy (CRT) proved to be an effective strategy to improve left ventricular function independently of age [24]. Importantly, CRT is able to produce, after only 6 months, an increase of physical performance, as evaluated with SPPB, and a positive effect on neuro-cognition, as evaluated with the Mini-Mental State Examination [25]. However, prognosis in CRT elderly patients is negatively influenced by the presence of AF [24]. In the APAF-CRT trial, permanent AF patients with HF (mean age $>70$ years; mean EF: 40\%) and narrow QRS were stratified to rate control strategy or to AV node ablation and CRT therapy. After 16 months of follow-up, hospitalizations for HF were significantly reduced in the group receiving the device, with an effect particularly evident in patients with an $\mathrm{EF} \leq 35 \%$. The invasive strategy had an influence also on healthrelated quality of life [26].

\section{Conclusions}

The interaction between $\mathrm{AF}$ and $\mathrm{HF}$ is complex. It can be responsible of some important complications of the arrhythmia, such as cognitive impairment, dementia and increased mortality. Inferring directional relationships between $\mathrm{AF}, \mathrm{HF}$ and the other outcomes can be treacherous. However, the comprehension of the mechanisms linking the arrhythmia to the several related clinical conditions can greatly help to clarify patients' prognosis [27]. Subjects with AF and HF need a multifaceted treatment strategy, as patients with only HF often do [28]. In this scenario, beta-blockers and digoxin seem to lose their relevance, while treatments addressed to reduce atrial remodeling are becoming more important. Rehabilitation programs and cardiac devices, two non-pharmacological approaches, could significantly ameliorate the clinical outcomes of patients with HF and AF.

\section{References}

1. Boriani G, Proietti M, Laroche C, et al. Contemporary stroke prevention strategies in 11096 European patients with atrial fibrillation: a report from the EURObservational Research Programme on Atrial Fibrillation (EORP-AF) Long-Term General Registry. Europace 2018;20:747-57. 
2. Chamberlain AM, Redfield MM, Alonso A, et al. Atrial fibrillation and mortality in heart failure: a community study. Circ Heart Fail 2011;4:740-6.

3. Santhanakrishnan R, Wang N, Larson MG, et al. Atrial Fibrillation begets heart failure and vice versa: Temporal associations and differences in preserved versus reduced ejection fraction. Circulation 2016;133:484-92.

4. Proietti M, Marra AM, Tassone EJ, et al. Frequency of left ventricular hypertrophy in non-valvular atrial fibrillation. Am J Cardiol 2015;116:877-82.

5. Thihalolipavan S, Morin DP. Atrial fibrillation and heart failure: update 2015. Prog Cardiovasc Dis 2015;58:126-35.

6. Fumagalli S, Tarantini F, Guarducci L, et al. Atrial fibrillation is a possible marker of frailty in hospitalized patients: results of the GIFA Study. Aging Clin Exp Res 2010;22:129-33.

7. Wijesurendra RS, Liu A, Eichhorn C, et al. Lone atrial fibrillation is associated with impaired left ventricular energetics that persists despite successful catheter ablation. Circulation 2016;134:1068-81.

8. Bajaj NS, Bhatia V, Sanam K, et al. Impact of atrial fibrillation and heart failure, independent of each other and in combination, on mortality in community-dwelling older adults. Am J Cardiol 2014;114:909-13.

9. Magnani JW, Wang N, Benjamin EJ, et al. Atrial fibrillation and declining physical performance in older adults: the health, aging, and body composition study. Circ Arrhythm Electrophysiol 2016;9:e003525.

10. Jefferson AL, Himali JJ, Beiser AS, et al. Cardiac index is associated with brain aging: the Framingham Heart Study. Circulation 2010;122:690-7.

11. Stefansdottir H, Arnar DO, Aspelund T et al. Atrial fibrillation is associated with reduced brain volume and cognitive function independent of cerebral infarcts. Stroke 2013;44:1020-5.

12. Knecht S, Oelschlager C, Duning T, et al. Atrial fibrillation in stroke-free patients is associated with memory impairment and hippocampal atrophy. Eur Heart J 2008;29:2125-32.

13. Kim JH, Shah P, Tantry US, Gurbel PA. Coagulation abnormalities in heart failure: pathophysiology and therapeutic implications. Curr Heart Fail Rep 2016;13:319-328.

14. Kirchhof P, Benussi S, Kotecha D, et al. 2016 ESC Guidelines for the management of atrial fibrillation developed in collaboration with EACTS. Europace 2016;18:1609-78.

15. Kotecha D, Holmes J, Krum H, et al. Efficacy of beta blockers in patients with heart failure plus atrial fibrillation: an individual-patient data meta-analysis. Lancet 2014;384: 2235-43.

16. Shah M, Avgil Tsadok M, Jackevicius CA, et al. Relation of digoxin use in atrial fibrillation and the risk of all-cause mor- tality in patients $>/=65$ years of age with versus without heart failure. Am J Cardiol 2014;114:401-6.

17. Lopes RD, Rordorf R, De Ferrari GM, et al. Digoxin and mortality in patients with atrial fibrillation. J Am Coll Cardiol 2018;71:1063-1074.

18. Fumagalli S, Gabbai D, Francini S, et al. External cardioversion of atrial fibrillation causes an early improvement of cardiac performance: A longitudinal strain analysis study. J Cardiovasc Echogr 2014;24:10-17.

19. Fumagalli S, Boni S, Pupo S, et al. Rate-control vs rhythmcontrol of atrial fibrillation in elderly patients. From new, ageoriented outcomes to a more complex management strategy. Monaldi Arch Chest Dis 2018;88:955.

20. Frasure-Smith N, Lesperance F, Habra M, et al. Elevated depression symptoms predict long-term cardiovascular mortality in patients with atrial fibrillation and heart failure. Circulation 2009;120:134-40, 3p following 140.

21. Frasure-Smith N, Lesperance F, Talajic M, et al. Anxiety sensitivity moderates prognostic importance of rhythm-control versus rate-control strategies in patients with atrial fibrillation and congestive heart failure: insights from the Atrial Fibrillation and Congestive Heart Failure Trial. Circ Heart Fail 2012;5:322-30.

22. Sanders P, Elliott AD, Linz D. Upstream targets to treat atrial fibrillation. J Am Coll Cardiol 2017;70:2906-2908.

23. Rienstra M, Hobbelt AH, Alings M, et al. Targeted therapy of underlying conditions improves sinus rhythm maintenance in patients with persistent atrial fibrillation: results of the RACE 3 trial. Eur Heart J 2018;39:2987-96.

24. Fumagalli S, Valsecchi S, Boriani G, et al. Comparison of the usefulness of cardiac resynchronization therapy in three agegroups ( $<65,65-74$ and $>/=75$ Years) (from the InSync/InSync ICD Italian Registry). Am J Cardiol 2011;107:1510-6.

25. Fumagalli S, Pieragnoli P, Ricciardi G, et al. Cardiac resynchronization therapy improves functional status and cognition. Int J Cardiol 2016;219:212-7.

26. Brignole M, Pokushalov E, Pentimalli F, et al. A randomized controlled trial of atrioventricular junction ablation and cardiac resynchronization therapy in patients with permanent atrial fibrillation and narrow QRS. Eur Heart J 2018;39:3999-4008.

27. Chen LY, Chung MK, Allen LA, et al. Atrial fibrillation burden: moving beyond atrial fibrillation as a binary entity: a scientific statement from the American Heart Association. Circulation 2018;137:e623-e644.

28. Fumagalli S, Fattirolli F, Guarducci L, et al. Coenzyme Q10 terclatrate and creatine in chronic heart failure: a randomized, placebo-controlled, double-blind study. Clin Cardiol 2011;34: 211-7. 